\title{
An evaluation of efficiency in an emergency laboratory by turnaround time
}

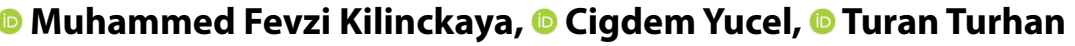 \\ Department of Clinical Biochemistry, Ankara Numune Training and Research Hospital, Ankara, Turkey
}

\begin{abstract}
Objectives: Accuracy, precision, timeliness, and authenticity are the 4 pillars of efficient laboratory services. Clinical biochemists generally overlook timeliness as an important attribute. However, turnaround time (TAT) is usually regarded by clinicians as the benchmark of laboratory performance. TAT can be classified by tests: priority, population served, etc. The aim of the current study was to both evaluate and compare the TAT of the test panels used in the emergency laboratory of Ankara Numune Training and Research Hospital.

Methods: The TAT for tests carried out in the emergency laboratory in 2016 was recorded. The TAT limit for each analyte was determined by the hospital's quality control department. Routine biochemistry, arterial blood gas, troponin, erythrocyte sedimentation rate, complete blood count, beta-human chorionic gonadotropin, coagulation panel, and urinalysis tests were evaluated. Samples were grouped by admission time, day, and staff on duty. Samples that exceeded the TAT limit were determined and compared in terms of sample receipt time, day, and staffing. Statistical analysis was performed using SPSS for Windows, Version 15.0 (SPSS Inc., Chicago, IL, USA). P $<0.05$ was considered statistically significant.

Results: A total of 286,577 samples were analyzed in 2016 in this laboratory. The TAT of 30,129 samples exceeded the established time limit. The mean TAT of the staff who worked a day shift on weekdays was significantly higher than that of other shifts, with the exception of arterial blood gas (ABG) testing ( $p=0.000$ for all panels). The mean TAT of the staff who worked a night shift on weekdays and weekends was statistically different, excluding coagulation $(p=0.08)$ and ABG $(p=0.09)$ tests.

Conclusion: It is strongly recommended that all of the staff who work in the laboratory be sufficiently informed and educated about TAT. Additionally, evaluation of TAT should be taken into consideration in the routine workflow of laboratories.
\end{abstract}

Keywords: Emergency laboratory, laboratory quality, turnaround time

$\mathrm{Q}$ uality can be defined as the ability of a product or service to satisfy the needs and expectations of the customer [1]. Laboratories have traditionally restricted discussion of quality to technical or analytical quality, focusing on imprecision and inaccuracy [2]. However, timeliness and accuracy are other terms of efficient laboratory management. While they share the concerns of laboratories, clinicians are also interested in the larger quality of service that laboratories offer, including areas such as the cumulative total of test errors, availability, cost, rele- vance, and timeliness. They need rapid and efficient laboratory service at a low cost [3]. Turnaround time (TAT) can be defined as a marker of timeliness; therefore, it can be used to evaluate the performance of laboratory.

According to Lundberg [4], it is necessary to achieve the following steps to perform a laboratory test: ordering, collection, identification, transportation, preparation, analysis, reporting, interpretation, and action. Lundberg also identified the brainto-brain TAT or "total testing cycle" using that 9-step series [5].

Address for correspondence: Muhammed Fevzi Kilinckaya, MD. Department of Clinical Biochemistry, Ankara Numune Training and Research Hospital, Ankara, Turkey

Phone: +90 5067947192 E-mail: mfkilinckaya@gmail.com ORCID: 0000-0002-0815-5467

Submitted Date: November 16, 2017 Accepted Date: January 15, 2018 Available Online Date: June 01 , 2018

${ }^{\circ}$ Copyright 2018 by International Journal of Medical Biochemistry - Available online at www.internationalbiochemistry.com 
However, most laboratories have limited the TAT to their intralaboratory activities just because they have the ability to control that part.

Intra-laboratory TAT can be defined as the time interval between sample acceptance or registration time to analytical completion time or result verification time or result transfer to electronic medical record time.

According to the College of American Pathologists (CAP) QProbes quality improvement program [6], 41\% of laboratories defined emergency department (ED) TAT as beginning at the time of receipt in the laboratory and continuing until time of report, while more than $40 \%$ of clinicians defined ED TAT as starting at the clinician's request.

The literature about TAT expectations and evaluations is limited. ED TAT for hemoglobin, potassium, glucose, and partial pressure of oxygen measurements were evaluated in the 1990 CAP Q-Probe study [7]. Following that, in 2004, the TAT of myocardial injury biochemical markers was investigated by both clinicians and laboratory personnel [8]. Recently, Lu et al. [9] and Chien et al. [10] evaluated turnaround time in a stat laboratory.

ED overcrowding is always one of the most severe health problems in medical care systems worldwide. As a result, a delayed TAT may be observed in the ED. Delayed TAT also increases the frequency of duplicate samples sent to the laboratory, thereby increasing the workload of the laboratory personnel. The aim of this study was to evaluate and compare the TAT of test panels in the emergency laboratory of Ankara Numune Training and Research Hospital in terms of the criteria of our quality department and to compare the frequency of delayed TAT according to laboratory staffing.

\section{Materials and Methods}

The study was designed to evaluate the TAT in an emergency laboratory during 2016. TAT was defined as the time interval between the sample acceptance time and result verification time. In the Ankara Numune Training and Research Hospital Emergency laboratory, analysis of arterial blood gas (ABG) (ABL 800; Radiometer Medical, Bronshoj, Denmark), troponin I (ACcess II; Beckman Coulter, Brea, CA, USA), beta-human chorionic gonadotropin ( $\beta$-hCG) (Access II), routine biochemistry panel (AU 5800; Beckman Coulter, Brea, CA, USA) (glucose, urea, creatinine, albumin, alanine transaminase, aspartate transaminase, alkaline phosphatase, gamma glutamyl transferase, sodium, potassium, chloride, calcium, uric acid, total and direct bilirubin, creatine kinase-muscle/brain), erythrocyte sedimentation rate (ESR) (ALIFAX Test 1; Alifax, Polverara Italy), urinalysis (Iris; Beckman Coulter, Brea, CA, USA), coagulation panel (ACL 700; Beckman Coulter, Brea, CA, USA) (activated partial thromboplastin time, prothrombin time, international normalized ratio, D-dimer, fibrinogen) and complete blood count (CBC) (LH 780; Beckman Coulter, Brea, CA,USA) are performed 24 hours a day, 7 days a week. The quality department of the hospital determined the TATs of the emergency laboratory as follows: 20 min- utes for $A B G, 30$ minutes for $C B C$ and urinalysis, 60 minutes for ESR, 90 minutes for a biochemistry panel, and troponin I and $\beta$-hCG level tests.

The laboratory staff were assigned into 2 groups: a day shift (08:00-16:00) of workdays (Monday, Tuesday, Wednesday, Thursday, Friday) (Group 1) and a night shift (16:00-08:00) of workdays and the weekend (Saturday, Sunday) (Group 2). Group 1 had 8 members. There were 4 subgroups (Group A, B, C, and D) in Group 2; they work every 4 days. Group 2 had 24 members who were recruited into each subgroup equally so that each had 6 members. The members of Group 2 were distributed randomly into Group A, B, C, and D.

The samples were grouped in terms of panel and sample receipt day and time via FONET LIS, the laboratory information system used by the hospital. The samples were sub grouped according to the staff members who had performed the analysis. Result verification times of samples were also retrieved from the system. The time interval between sample acceptance and result verification was considered the TAT. The TAT of the samples and that determined by the hospital's quality department were compared in order to determine delayed TAT samples.

Samples that were rejected for various reasons (such as hemolysis, lipemia, and icterus) and misidentified samples were not included in the study. Samples without an acceptance time were also excluded.

Statistical analyses were performed with SPSS for Windows, Version 15.0 (SPSS Inc., Chicago, IL, USA). After the frequency of samples with a TAT beyond the hospital standard was determined, the proportion of these samples to all samples of all groups was compared with a chi-square test. $\mathrm{P}<0.05$ was considered statistically significant.

\section{Results}

The analysis of 286.577 samples was performed in our emergency laboratory in 2016. A total of 30.129 (10.51\%) samples had a TAT exceeding the recommendation. The frequency of samples with a delayed TAT is shown in Table 1 according to test panel.

Group 1 (weekdays, day shift) performed 67,558 sample analy-

\section{Table 1. Frequency of samples with delayed turnaround time}

Test Panel

Samples with

delayed TAT

(n)

\begin{tabular}{lccc}
\hline Urinalysis & 3661 & 23163 & 15.80 \\
ESR & 475 & 3938 & 12.06 \\
Routine biochemistry & 5051 & 82541 & 6.11 \\
ß-hCG & 974 & 7817 & 12.46 \\
ABG & 5669 & 31062 & 18.25 \\
Troponin I & 1191 & 31166 & 3.82 \\
CBC & 10921 & 83375 & 13.09 \\
Coagulation & 2187 & 23515 & 9.30 \\
Total & 30129 & 286577 & 10.51
\end{tabular}

Rate

(\%) (n)

(n) 
Table 2. Frequency of delayed samples according to staffing

\begin{tabular}{|c|c|c|c|c|c|c|c|c|c|c|c|c|c|}
\hline \multirow[t]{2}{*}{ Test Panel } & \multicolumn{3}{|c|}{$\begin{array}{c}\text { Group } 1 \\
\text { (Weekdays and day shift) }\end{array}$} & \multicolumn{3}{|c|}{$\begin{array}{c}\text { Group } 2 \\
\text { (Weekdays and night shift) }\end{array}$} & \multicolumn{3}{|c|}{$\begin{array}{c}\text { Group } 2 \\
\text { (Weekends) }\end{array}$} & \multirow[t]{2}{*}{$\mathbf{p}_{1-2-3}$} & \multirow[t]{2}{*}{$\mathbf{p}_{1-2}$} & \multirow[t]{2}{*}{$\mathbf{p}_{1-3}$} & \multirow[t]{2}{*}{$\mathbf{p}_{2-3}$} \\
\hline & $\begin{array}{c}\text { Samples } \\
\text { with } \\
\text { delayed } \\
\text { TAT (n) }\end{array}$ & $\begin{array}{c}\text { Total } \\
\text { samples } \\
\text { (n) }\end{array}$ & $\begin{array}{l}\text { Rate } \\
\text { (\%) }\end{array}$ & $\begin{array}{c}\text { Samples } \\
\text { with } \\
\text { delayed } \\
\text { TAT (n) }\end{array}$ & $\begin{array}{c}\text { Total } \\
\text { samples } \\
\text { (n) }\end{array}$ & $\begin{array}{l}\text { Rate } \\
\text { (\%) }\end{array}$ & $\begin{array}{c}\text { Samples } \\
\text { with } \\
\text { delayed } \\
\text { TAT (n) }\end{array}$ & $\begin{array}{c}\text { Total } \\
\text { samples } \\
\text { (n) }\end{array}$ & $\begin{array}{l}\text { Rate } \\
\text { (\%) }\end{array}$ & & & & \\
\hline ESR & 150 & 886 & 16.93 & 266 & 2470 & 10.76 & 59 & 582 & 10.13 & $<0.01$ & $<0.01$ & $<0.01$ & 0.16 \\
\hline Routine & 1668 & 18357 & 9.08 & 2215 & 38333 & 5.77 & 1168 & 25851 & 4.51 & $<0.01$ & $<0.01$ & $<0.01$ & $<0.01$ \\
\hline \multicolumn{14}{|l|}{ Biochemistry } \\
\hline$\beta-h C G$ & 661 & 2149 & 30.75 & 179 & 3384 & 5.28 & 134 & 2284 & 5.86 & $<0.01$ & $<0.01$ & $<0.01$ & 0.37 \\
\hline$A B G$ & 1468 & 7882 & 18.62 & 2743 & 13615 & 20.14 & 1458 & 9565 & 15.24 & 0.8 & $<0.01$ & $<0.01$ & 0.2 \\
\hline
\end{tabular}

ABG: Arterial blood gas; ESR: Erythrocyte sedimentation rate; $\beta$-hCG: Beta-human chorionic gonadotropin; TAT: Turnaround time.

p1-2-3: Comparison of Group 1, Group 2, and Group 3; p 1-2: Comparison of Group 1 and 2; p1-3: Comparison of Group 1 and 3; p2-3: Comparison of Group 2 and 3 statistically significance: $p<0.05$

Table 3. Frequency of all samples and samples with delayed turnaround time according to Group 2 subgroup

\begin{tabular}{|c|c|c|c|c|c|c|c|c|c|c|c|c|}
\hline Test Panel & \multicolumn{3}{|c|}{ Group A } & \multicolumn{3}{|c|}{ Group B } & \multicolumn{3}{|c|}{ Group C } & \multicolumn{3}{|c|}{ Group D } \\
\hline ESR & 97 & 705 & 13.76 & 97 & 800 & 12.13 & 69 & 817 & 8.45 & 62 & 730 & 8.49 \\
\hline $\begin{array}{l}\text { Routine } \\
\text { Biochemistry }\end{array}$ & 945 & 16441 & 5.75 & 758 & 15632 & 4.85 & 851 & 16083 & 5.29 & 829 & 16028 & 5.17 \\
\hline$\beta$-hCG & 91 & 1492 & 6.10 & 50 & 1376 & 3.63 & 88 & 1330 & 6.62 & 84 & 1470 & 5.71 \\
\hline$A B G$ & 981 & 5813 & 16.88 & 1003 & 5830 & 17.20 & 1058 & 5755 & 18.38 & 1080 & 5782 & 18.68 \\
\hline
\end{tabular}

ABG: Arterial blood gas; CBC: Complete blood count; ESR: Erythrocyte sedimentation rate; $\beta$-hCG: Beta-human chorionic gonadotropin; TAT: Turnaround time Group 2: Staff who work in night shift (16:00-08:00) of workdays and also work in weekends.

ses. Of those, 9916 (14.65\%) had a longer than expected TAT. Group 2 performed the analysis of 129,576 samples (night shift and weekends), and 12.755 (9.84\%) had a TAT that was longer than desired. Group 2 tested 89,343 samples on weekends, and 7458 (8.34\%) had a longer TAT.

The proportion of samples with a long TAT was examined in relation to all analyzed samples. Group 1 had a significantly longer TAT compared with Group $2(p=0.000)$. When the rela- tionship between staffing and test panels was evaluated, it was observed that Group 1 had a greater rate of exceeding the predetermined TAT compared with Group 2 ( $p=0.00$ for all sample groups), with the exception of $A B G(p=0.08)$. The frequency of samples according to staffing and the analysis performed is provided in Table 2.

Group 2 was divided into 4 subgroups according to work days: Group A analyzed 55,814 samples, and 5459 (9.78\%) had a de- 
Table 4. Comparison of delayed turnaround time in Group 2 subgroups

\begin{tabular}{|c|c|c|c|c|c|c|c|}
\hline \multirow[t]{2}{*}{ Test Panel } & \multicolumn{7}{|c|}{ p values } \\
\hline & $\mathbf{p}_{\text {A-B-C-D }}$ & $\mathbf{p}_{\mathrm{A}-\mathrm{B}}$ & $\mathbf{p}_{\mathrm{A}-\mathrm{C}}$ & $\mathbf{p}_{\mathrm{A}-\mathrm{D}}$ & $\mathbf{p}_{\mathrm{B}-\mathrm{C}}$ & $\mathbf{p}_{\text {B-D }}$ & $\mathbf{p}_{C-D}$ \\
\hline ESR & $<0.01$ & 0.40 & $<0.01$ & $<0.01$ & 0.02 & 0.03 & 1.09 \\
\hline \multicolumn{8}{|l|}{ Routine } \\
\hline$A B G$ & 0.09 & 0.69 & 0.07 & 0.03 & 0.16 & 0.08 & 0.73 \\
\hline Troponin I & $<0.01$ & 0.07 & 0.21 & 0.25 & $<0.01$ & 0.52 & 0.01 \\
\hline $\mathrm{CBC}$ & $<0.01$ & $<0.01$ & $<0.01$ & $<0.01$ & 0.33 & $<0.01$ & 0.06 \\
\hline Coagulation & 0.08 & 0.50 & 0.06 & 0.85 & 0.01 & 0.40 & 0.09 \\
\hline Total & $<0.01$ & $<0.01$ & $<0.01$ & $<0.01$ & 1.06 & 0.16 & 0.17 \\
\hline
\end{tabular}

layed TAT; Group B analyzed 53,687 samples, and 4869 (9.06\%) were delayed; Group C analyzed 54,016 samples, and 4895 (9.06\%) had a delayed TAT; and Group D analyzed 55.752 samples, of which 4911 (8.80\%) were delayed. The frequency of the samples with a delayed TAT is illustrated in Table 3 in terms of test panel and the subgroups of Group 2.

With the exception of coagulation $(p=0.08)$ and ABG $(p=0.09)$, there were significant differences among other test panels in terms of frequency of delayed TAT of samples $(p<0.001$ for all test panels). The frequency of delayed TAT in Group 2 is compared by subgroup in Table 4. Our results indicated that the frequency of a delayed TAT was statistically different in a comparison between Groups A and D; however, only 2 of 9 test panel groups was statistically different between Groups $C$ and D.

\section{Discussion}

Clinicians are dependent on laboratory results to manage the care of their patient. Clinical biochemists should pay more attention to improving laboratory efficiency. It is of critical importance to know that the pre- and post-analytical phases are just as important as the analytical phase [9].

The speed with which laboratory results are reported impacts the institution as well as the patient [11]. When the results of routine laboratory tests are delayed, physicians have a tendency to reorder the same test $[12,13]$. Therefore, there is now an increase in the importance given to the determination and evaluation of sample TATs.

Although the TAT is important for all laboratories, for emer- gency laboratories, it has a more critical role, as fast and accurate results are the main goal of these laboratories. Articles in the literature examining TAT also specify that it is particularly critical for the emergency laboratory because of the importance of time. Cheng et al. [14] evaluated the TAT of an emergency department after the installation of a computerized auto verification process and they concluded that statistically significant improvements were recorded for a basic metabolic panel, a comprehensive metabolic panel, and troponin I tests. Goswani et al. [15] also investigated the TAT of samples in routine and emergency laboratories for electrolytes prothrombin time testing. They also educated the medical personnel who worked in all phases of the laboratory cycle and implemented methods that led to significant improvement [15].

The TATs of our study are listed in Table 2. The predetermined acceptable delayed result percentage is $10 \%$ for our emergency laboratory. Only the TAT of Group 1 exceeded the 10\% ratio; all of the subgroups of Group 2 were within the limit. Yet we still need to improve our TAT ratios, as the main goal of the emergency laboratory is to provide the most accurate results in the shortest time.

We also analyzed the TAT according to laboratory staffing, as we had recently received some official complaints. We observed that the total frequency of delayed TAT in Group 2 was below the limit; however, there were significant differences between the subgroups. The members of the groups had a similar number of years of experience and level of competence. We did not have sufficient information to explain the differences. 
Hawkins et al. [2] proposed that completion time (sample registration to reporting of results) of $90 \%$ in $<60$ minutes was an initial goal for an acceptable TAT for potassium analysis. Steindel et al. [6] also found that 690 hospital laboratories reported that $90 \%$ of potassium results were ordered and reported in 69 minutes or less.

Studies in the literature focus on the improvement of TAT. Groenewald et al. [16] investigated the effect of pneumatic tube systems and new automated chemistry analytical systems on TAT, and they found significant improvement in the potassium results after establishing pneumatic tube system, as well as significant improvement in troponin $\mathrm{T}$ test results after installing a new automated chemistry analyzer. In the present study we only considered the accepted TAT determined by the hospital.

Our study was different in some aspects from previous research. First, we aimed to determine the ratio of delayed TAT in our emergency laboratory according to staffing groups due to recent TAT complaints from the quality department of the hospital. We observed that samples requiring centrifugation had the highest rate of delayed TAT in Group 1. We think that there may be a disconnection between sample acceptance and initiation of the analytical phase. Secondly, we aimed to observe the TAT of analytes. Similar to other studies, we also focused on troponin, the TAT of which is important; however, we found that the frequency of delayed $\beta$-hCG results was significantly higher in Group 1 compared with Group 2 (30.75\% vs. 5.28\%, respectively). While the delayed TAT of troponin in Group 1 was also significantly higher than that of Group 2, the difference was smaller than that of $\beta$-hCG. (5.67\% vs. 3.36\%).

One of the benefits to our study is pointing out TAT results for other important analytes and measures beyond troponin, such as coagulation and $\beta$-hCG.

Our study has some limitations. We did not separate and reanalyze samples by re-grouping in terms of admission time or month. This may be important, because some staff members in both Group 1 and Group 2 had used their annual leave, so re-analyzing TAT with regard to admission month could help us to clarify that situation. Also, the workload of the laboratory changes seasonally and monthly. Delays in workflow are more likely to occur with more intense studies and increased sample numbers. Recording of TATs according to admission month will also give us a better understanding of this perspective. Furthermore, we do not have sufficient information about the TAT of samples after corrective and preventive action is implemented. With those results in hand, we will have the power to see the exact effects of corrective action on TAT.

\section{Conclusion}

Despite improvements in sample transportation, the analytical phase, and the reporting system, TAT may still be defined as a source of difficulty between laboratory personnel and clinicians. We, as clinical biochemists, should adopt new approaches and policies to achieve optimum TAT.
Conflict of interest: None declared.

Peer-review: Externally peer-reviewed.

Authorship contributions: Concept - M.F.K., T.T.; Design - M.F.K.; Supervision - T.T.; Fundings - T.T.; Materials - M.F.K.; Data collection \&/or processing - M.F.K.; Analysis and/or interpretation - M.F.K., C.Y.; Literature search - M.F.K., C.Y.; Writing - M.F.K., C.Y.; Critical review - T.T.

\section{References}

1. Bergman B, KlefsjO, B. Quality: FromCustomer Needs to Customer Satisfaction. London: McGraw-Hill; 1994.

2. Hawkins RC. Laboratory turnaround time. Clin Biochem Rev 2007;28:179-94.

3. Neuberger J, Peters M. The clinical interface-a British physician's view. Clin Chim Acta 1996;248:11-8. [CrossRef]

4. Lundberg GD. Acting on significant laboratory results. JAMA 1981;245:1762-3. [CrossRef]

5. Crook MA. Near patient testing and pathology in the new millennium. J Clin Pathol 2000;53:27-30. [CrossRef]

6. Steindel SJ, Howanitz PJ. Physician satisfaction and emergency department laboratory test turnaround time. Arch Pathol Lab Med 2001;125:863-71.

7. Howanitz PJ, Cembrowski GS, Steindel SJ, Long TA. Physician goals and laboratory test turnaround times. A College of American Pathologists Q-Probes study of 2763 clinicians and 722 institutions. Arch Pathol Lab Med 1993;117:22-8.

8. Novis DA, Jones BA, Dale JC, Walsh MK. College of American Pathologists. Biochemical markers of myocardial injury test turnaround time: a College of American Pathologists Q-Probes study of 7020 troponin and 4368 creatine kinase-MB determinations in 159 institutions. Arch Pathol Lab Med 2004;128:158-64.

9. Lu Y, Leong W, Wei B, Yu P, Wang C, Ying Y, et al. An Evaluation of Laboratory Efficiency in Shanghai Emergency by Turn Around Times Level. J Clin Lab Anal 2015;29:334-41. [CrossRef]

10. Chien TI, Lu JY, Kao JT, Cheng YC, Lee YF. Evaluation and improvement strategy of analytical turnaround time in the stat laboratory. J Formos Med Assoc 2007;106:558-64. [CrossRef]

11. Valenstein P. Laboratory turnaround time. Am J Clin Pathol 1996;105:676-88. [CrossRef]

12. Barnett RN, Bimmell M. Peracca M, Rosemann K. Time intervals between ordering and obtaining laboratory test results. Patholo- gist 1975;29:3-8.

13. Valenstein P, Leiken A, Lehmann C. Test-ordering by multiple physicians increases unnecessary laboratory examinations. Arch Pathol Lab Med 1988;112:238-41.

14. Cheng P, Rieta R, Bowen RAR. Evaluation of turn-around-time (TAT) of emergency department specimens after computerized autoverification. Clin Biochem. 2008;41:1265. [CrossRef]

15. Goswami B, Singh B, Chawla R, Gupta VK, Mallika V.Turn Around Time (TAT) as a Benchmark of Laboratory Performance. Indian J Clin Biochem 2010;25:376-9. [CrossRef]

16. Groenewald AJ, Potgieter HD. Physician satisfaction and emergency (stat) laboratory turnaround time during various developmental stages. Med Technol 2014;28:20-5. 